\title{
Effects of a stimulus associated with fixed-ratio postreinforcement pause in the rat
}

\author{
GARTH HINES \\ University of Arkansas, Little Rock, Arkansas
}

\begin{abstract}
Rats presented with a stimulus paired with the postreinforcement pause (PRP) of fixed-ratio (FR) responding showed a temporary decrease in PRP and pause duration between the first and second responses. This suppression of pausing increased with increased ratio magnitude, and recovery from suppression was slower at the higher requirement. These results are consistent with an interpretation involving acquired punishing properties by the PRP-paired stimulus, and suggest that the PRP represents an avoidance response wherein the FR response requirement itself serves as an aversive condition with increases in its negative properties as the FR magnitude increases.
\end{abstract}

Ferster and Skinner (1957) suggested that the long postreinforcement pause (PRP) durations found at high fixedratio (FR) values are due to the suppressive effect of stimuli then present. The notion that the PRP represents a response to an aversive condition received support from the findings that aggressive responses are emitted during the PRP of FR schedules, with the magnitude of the aggression related to the FR magnitude (Cherek \& Pickens, 1970; Gentry, 1968; Hutchinson, Azrin, \& Hunt, 1968; Turner \& Lyon, 1970). Furthermore, subjects will respond to produce time out (TO) from FR schedules, with TO responding largely limited to the PRP and increasing with increases in FR magnitude (Appel, 1963; Azrin, 1961). The reinforcing nature of the TO is further indicated by the observation (Thompson, 1964) that responding for TO during FR schedules can itself be brought under FR schedule control.

Butler (1972) paired the pause and run components of the pigeon's FR responding with different colored stimuli in an attempt to determine the degree to which these response patterns could be brought under stimulus control. Under these conditions, some of his subjects would show an abbreviated PRP (thus rapidly turning off the pause-related stimulus and turning on the run-related stimulus), followed by a lengthy pause between the first $\left(R_{1}\right)$ and second $\left(R_{2}\right)$ responses. This finding suggests that the pause-related stimulus had acquired secondary aversive properties, with $R_{1}$ representing an escape response (terminating the pause-related stimulus). However, since the factors initially inducing the PRP were then still present, the pause was continued in the $R_{1}-R_{2}$ interval. The present study was intended to further investigate the influence of a PRP-paired stimulus on responding on FR schedules.

This research was funded by the Marie Wilson Howells bequest to the Psychology Department of the University of Arkansas at Little Rock. Correspondence may be addressed to Garth Hines, Department of Psychology, University of Arkansas at Little Rock, Little Rock, AR 72204.

\section{METHOD}

\section{Subjects}

Six male Holtzman albino rats, approximately 90 days old, were used as subjects. All were placed on a deprivation schedule consisting of $15 \mathrm{~min}$ of daily access to water-given in the home cage at the end of each day's testing run-with food continuously available. This schedule produced a decrease in the rats' growth rates, but did not stop a steady increase in body weight from occurring over the duration of the experiment.

\section{Apparatus}

The subjects were tested in a Grason-Stadler Model 1111 rat chamber, with the right level and stimulus light removed and the spaces covered with stainless steel. The chamber was contained in a sound-insulated Grason-Stadler Model 1101 research chest, with an exhaust fan providing masking noise. Responses were recorded and reinforcements delivered (using a Gerbrands Model GS-RH liquid dipper) by BRS Series 100 programming modules.

Measurements were taken of PRP and $R_{1}-R_{2}$ durations, response rate from $R_{\mathbf{A}}-\mathbf{R}_{N}$ (referred to as the terminal run rate), and reinforcement density.

\section{Procedure}

All subjects were trained to barpress for water reinforcement $(0.04 \mathrm{ml}$ tap water, 3-sec access) on an FR16 schedule. After PRP and terminal run rate had stabilized-using a criterion of 5 consecutive days in which the mean value did not deviate from the mean of the preceding 5 days by an amount greater than $\pm 15 \%$ - a light stimulus was introduced during the PRP. This light (12-V dc bulb behind a white frosted lens, located above and to the left of the lever) was turned on at the termination of reinforcement delivery and remained on until $R_{1}$ emission. After 15 daily sessions ( 50 reinforcements per session), the light stimulus was removed, and the subjects were returned to baseline. The schedule was then increased to FR32, and PRP and terminal run rate were stabilized. The light stimulus was then reintroduced during the PRP. After 15 sessions, the stimulus was again removed, baseline was recovered, and the experiment was terminated. A descending sequence of ratio magnitude was not used, since Thompson (1964) had indicated that descending series essentially recovered ascending values, at least insofar as TO responding was concerned.

\section{RESULTS}

The results were collapsed into three-session blocks, and suppression ratios (SRs) were determined for each of the four measures by the formula 


$$
\mathrm{SR}=X_{\text {block }} /\left[\left(X_{\text {pretest base }}+X_{\text {recovery base }}\right) / 2\right] .
$$

Both the pretest and the recovery baseline values were used in the computation to account for any gradual trend that might have occurred across the experimental sessions. In fact, the recovered baselines did closely approximate the pretest values for all subjects except PRPS5, whose recovery baseline on FR16 showed markedly longer PRP values.

Mean suppression ratios across all subjects are shown in Figure 1. Since these mean values are quite representative of the data from individual subjects (Table 1), no statistical analyses were performed.

In general, the introduction of a stimulus paired with the FR PRP produced a temporary decrease in PRP duration, followed by a return to prestimulus values. Suppression was greater, and recovery slower, at FR32 than at FR16. Although the individual values were all within the stability criterion range at FR16, the consistency of the pattern across subjects (for example, all subjects produced their minimum PRP during the second session block) suggests that this was a stimulus conditionproduced effect. At FR32, all subjects again produced a U-shaped PRP distribution, with maximal suppression for 3 of the subjects falling well outside the $\pm 15 \%$ range.

Contrary to expectation, $\mathbf{R}_{\mathbf{1}}-\mathbf{R}_{\mathbf{2}}$ duration was not lengthened. Rather, it showed (to a lesser degree) the same tem- porary suppression as did the PRP, with the degree of suppression related to the FR magnitude. With the exception of PRPS2, which showed a steady decline in duration at FR32, all subjects recovered toward baseline values within the 15 test sessions.

There was no consistent across-blocks trend insofar as terminal run rates were concerned, although there was some tendency for the rates to be slightly elevated throughout the stimulus-test sessions.

These values-PRP, $R_{\mathbf{1}}-\mathbf{R}_{\mathbf{2}}$ duration, and run ratecombined to produce changes in the reinforcement rate that were the inverse of the pattern seen for the PRP and $\mathbf{R}_{\mathbf{1}}-\mathbf{R}_{\mathbf{2}}$ measures. That is, reinforcement density increased to a maximum, then declined to near baseline values. As with the previous measures, the degree and duration of change was greatest at the higher FR value.

\section{DISCUSSION}

To the degree that the conditions producing the FR PRP are aversive, neutral stimuli paired with those conditions might be expected to take on secondary aversive properties. The present study provides support for this notion, and further suggests that the aversive properties are related to the magnitude of the ratio requirement. The PRP was found to be temporarily suppressed by the addition of a neutral stimulus which, through its acquired aversive properties, effectively punishes the pause. Consistent with Azrin's (1960) results, this suppression showed recovery to baseline as punishment continued, with the magnitude of the sup-
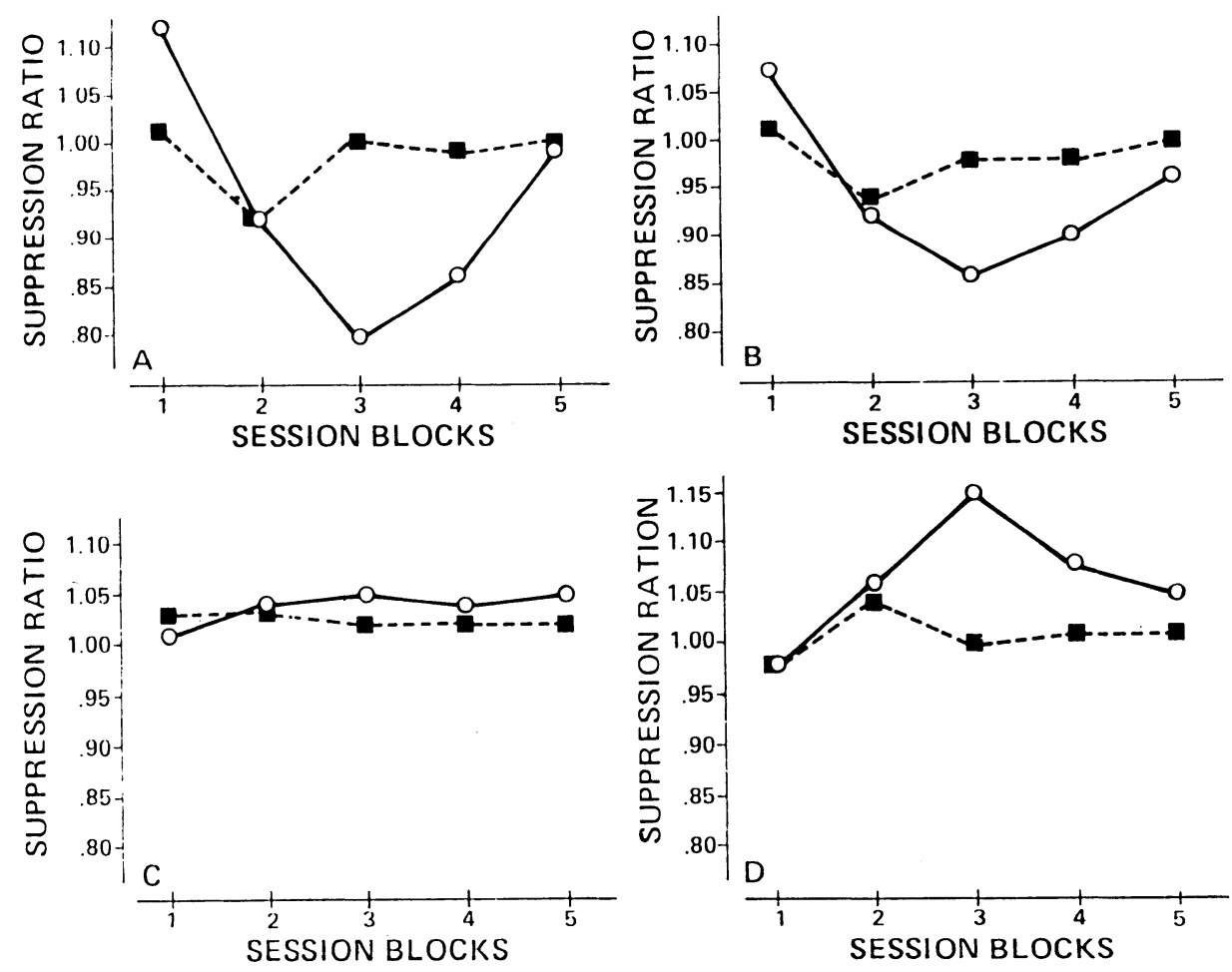

Figure 1. Mean suppression ratios averaged across subjects, as a function of session blocks (three sessions per block). (A) Postreinforcement pause duration. (B) $\mathbf{R}_{\mathbf{1}}-\mathbf{R}_{\mathbf{2}}$ duration. (C) Terminal run rate. (D) Reinforcement rate. Closed squares refer to FR16, and open circles to FR32. 
Table 1

Suppression Ratios by Session Blocks for Each Subject

\begin{tabular}{|c|c|c|c|c|c|c|c|c|c|c|}
\hline \multirow[b]{2}{*}{ Subject } & \multicolumn{5}{|c|}{ FR16 Block } & \multicolumn{5}{|c|}{ FR32 Block } \\
\hline & 1 & 2 & 3 & 4 & 5 & 1 & 2 & 3 & 4 & 5 \\
\hline \multicolumn{11}{|c|}{ Postreinforcement Pause } \\
\hline $\begin{array}{l}\text { PRPS1 } \\
\text { PRPS2 } \\
\text { PRPS3 } \\
\text { PRPS4 } \\
\text { PRPS5 } \\
\text { PRPS6 }\end{array}$ & $\begin{array}{r}1.11 \\
1.01 \\
.96 \\
.97 \\
.99 \\
1.02\end{array}$ & $\begin{array}{l}.93 \\
.95 \\
.86 \\
.91 \\
.95 \\
.91\end{array}$ & $\begin{array}{r}.99 \\
.97 \\
.95 \\
.94 \\
1.07 \\
1.09\end{array}$ & $\begin{array}{r}.97 \\
.97 \\
1.01 \\
.99 \\
.99 \\
1.00\end{array}$ & $\begin{array}{r}1.01 \\
1.00 \\
.99 \\
.98 \\
1.02 \\
1.01\end{array}$ & $\begin{array}{r}1.01 \\
1.27 \\
1.34 \\
.95 \\
1.12 \\
1.04\end{array}$ & $\begin{array}{r}.94 \\
.91 \\
.83 \\
.79 \\
1.06 \\
1.04\end{array}$ & $\begin{array}{l}.94 \\
.71 \\
.72 \\
.56 \\
.93 \\
.96\end{array}$ & $\begin{array}{r}.89 \\
.72 \\
.92 \\
.65 \\
1.03 \\
.96\end{array}$ & $\begin{array}{r}1.07 \\
.87 \\
.93 \\
1.08 \\
1.00 \\
.99\end{array}$ \\
\hline \multicolumn{11}{|c|}{$\mathbf{R}_{\mathbf{1}}-\mathbf{R}_{\mathbf{2}}$ Duration } \\
\hline $\begin{array}{l}\text { PRPS1 } \\
\text { PRPS2 } \\
\text { PRPS3 } \\
\text { PRPS4 } \\
\text { PRPS5 } \\
\text { PRPS6 }\end{array}$ & $\begin{array}{r}1.10 \\
1.00 \\
.96 \\
.95 \\
1.02 \\
1.02\end{array}$ & $\begin{array}{r}1.00 \\
.94 \\
.90 \\
.89 \\
.96 \\
.95\end{array}$ & $\begin{array}{r}1.01 \\
.92 \\
.92 \\
.94 \\
1.06 \\
1.04\end{array}$ & $\begin{array}{r}.92 \\
.97 \\
.98 \\
.95 \\
1.03 \\
1.05\end{array}$ & $\begin{array}{r}1.01 \\
1.00 \\
.97 \\
.97 \\
1.04 \\
1.01\end{array}$ & $\begin{array}{r}1.08 \\
1.09 \\
1.09 \\
.93 \\
1.18 \\
1.03\end{array}$ & $\begin{array}{r}.79 \\
.88 \\
.98 \\
.74 \\
1.11 \\
1.03\end{array}$ & $\begin{array}{l}.98 \\
.79 \\
.92 \\
.60 \\
.89 \\
.99\end{array}$ & $\begin{array}{l}.97 \\
.79 \\
.95 \\
.79 \\
.97 \\
.93\end{array}$ & $\begin{array}{r}.94 \\
.75 \\
.98 \\
1.10 \\
.97 \\
.99\end{array}$ \\
\hline \multicolumn{11}{|c|}{ Terminal Run Rate } \\
\hline $\begin{array}{l}\text { PRPS1 } \\
\text { PRPS2 } \\
\text { PRPS3 } \\
\text { PRPS4 } \\
\text { PRPS5 } \\
\text { PRPS6 }\end{array}$ & $\begin{array}{r}.96 \\
1.05 \\
1.12 \\
1.02 \\
.98 \\
1.04\end{array}$ & $\begin{array}{r}.95 \\
1.02 \\
1.15 \\
1.03 \\
1.04 \\
.98\end{array}$ & $\begin{array}{r}.97 \\
1.04 \\
1.13 \\
.97 \\
1.03 \\
1.00\end{array}$ & $\begin{array}{r}1.00 \\
1.00 \\
1.09 \\
.97 \\
1.04 \\
1.02\end{array}$ & $\begin{array}{r}.98 \\
1.03 \\
1.11 \\
1.01 \\
1.00 \\
.98\end{array}$ & $\begin{array}{r}.93 \\
1.09 \\
1.04 \\
1.03 \\
.97 \\
1.02\end{array}$ & $\begin{array}{r}.92 \\
1.07 \\
1.17 \\
1.03 \\
.98 \\
1.06\end{array}$ & $\begin{array}{r}1.05 \\
1.05 \\
1.13 \\
.98 \\
1.04 \\
1.07\end{array}$ & $\begin{array}{r}1.04 \\
1.02 \\
1.13 \\
.99 \\
1.01 \\
1.03\end{array}$ & $\begin{array}{l}1.08 \\
1.05 \\
1.07 \\
1.06 \\
1.00 \\
1.08\end{array}$ \\
\hline \multicolumn{11}{|c|}{ Reinforcement Rate } \\
\hline $\begin{array}{l}\text { PRPS1 } \\
\text { PRPS2 } \\
\text { PRPS3 } \\
\text { PRPS4 } \\
\text { PRPS5 } \\
\text { PRPS6 }\end{array}$ & $\begin{array}{r}.94 \\
.99 \\
1.02 \\
1.02 \\
.96 \\
.97\end{array}$ & $\begin{array}{l}1.01 \\
1.02 \\
1.08 \\
1.06 \\
1.03 \\
1.04\end{array}$ & $\begin{array}{r}.99 \\
1.03 \\
1.04 \\
1.02 \\
.96 \\
.98\end{array}$ & $\begin{array}{r}1.02 \\
1.01 \\
1.03 \\
1.00 \\
.98 \\
.99\end{array}$ & $\begin{array}{r}1.01 \\
1.02 \\
1.03 \\
1.01 \\
.98 \\
.98\end{array}$ & $\begin{array}{r}.98 \\
.96 \\
.94 \\
1.02 \\
.98 \\
1.02\end{array}$ & $\begin{array}{r}1.00 \\
1.23 \\
1.03 \\
1.06 \\
.94 \\
1.07\end{array}$ & $\begin{array}{l}1.03 \\
1.25 \\
1.14 \\
1.26 \\
1.02 \\
1.20\end{array}$ & $\begin{array}{r}1.09 \\
1.20 \\
1.05 \\
1.16 \\
.95 \\
1.04\end{array}$ & $\begin{array}{l}.94 \\
1.15 \\
1.02 \\
1.13 \\
1.01 \\
1.02\end{array}$ \\
\hline
\end{tabular}

pression and the rate of recovery related to the magnitude of the ratio requirement (i.e., to the intensity of the aversive event).

This interpretation suggests that, under normal conditions, the PRP represents a period in which the subject is avoiding the FR run, with the strength of the tendency to avoid increasing with the ratio magnitude. Avoidance is not complete, however, since responding is reinforced immediately by a reduction in the number of required responses, and ultimately by delivery of the primary reinforcer. With the addition of the PRP-paired stimulus, the balance is further shifted toward responding, adding escape from punishment to the reinforcing value of responding. The net result is a temporary suppression of the (punished) pause. With continued exposure to the punishing stimulus, its effectiveness as a response suppressor diminishes, and the PRP returns to its initial value.

The $\mathbf{R}_{\mathbf{1}}-\mathbf{R}_{\mathbf{2}}$ data are also consistent with this interpretation. FR responding is generally described as a two-state process consisting of a PRP followed by a shift to a high rate of responding, which is sustained from the first response after reinforcement up to the last reinforced response (Reynold, 1968). Gott and Weiss (1972), however, have presented data that suggest that FR responding follows a three-state process, with a "junction zone" interposed between the PRP and the steady-state responding. Within this zone, the mean interresponse time was seen to decrease monotonically. The increasing response rate within the junction zone was related to an interaction between (1) the PRP, which dominates the period immediately following reinforcement and would generalize to adjacent interresponse times; and (2) the event of reinforcement. Thus, factors affecting PRP duration might be expected to exert a similar influence on responding early in the run, producing the similarity between $R_{1}-R_{2}$ and PRP duration effects. It might be noted in this regard that although Cherek and Pickens (1970) found aggression to occur predominantly during the PRP, some aggession also occurred early in the run. One explanation for the early-run interaction might be the fact that each response reduces the subsequent response requirement (and, therefore, the magnitude of the aversive condition) by an acceleratively increasing proportion, producing a decrease in the avoidance tendency until a point is reached at which the primary reinforcement effects are overwhelmingly dominant, and response rates become constant.

That the aversive nature of the ratio requirement is quite strong, even with low and moderate FRs, is suggested by the observation that a marked increase in reinforcement density (at FR32, 3 subjects increased their reinforcement density by $20 \%-26 \%$ and a 4 th by $14 \%$ ) was not sufficient to maintain the PRP and $R_{1}-R_{2}$ durations at their decreased values.

The initial increase in PRP and $R_{1}-R_{2}$ durations upon introduction of the light stimulus remains anamolous. That it does not represent an artifact produced by exploration of a novel stimulus is suggested by the observation that the increase was greatest for the FR32 condition, after the subjects had been thoroughly exposed to the light stimulus during FR16 testing.

\section{REFERENCES}

APPEL, J. B. (1963). Aversive aspects of a schedule of positive reinforcement. Journal of the Experimental Analysis of Behavior, 6 , 423-428.

Azrin, N. H. (1960). Sequential effects of punishment. Science, 131, 605-606.

Azrin, N. H. (1961). Time out from positive reinforcement. Science, 133, 382-383.

Butler, A. C. (1974). Separating the effects of pause vs. run during fixed ratio responding (Doctoral dissertation, University of Montana, 1974). Dissertation Abstracts International, XX, 3605B-3606B.

Cherex, D. R., \& Pickens, R. (1970). Schedule-induced aggression as a function of fixed-ratio value. Journal of the Experimental Analysis of Behavior, 14, 309-313.

FERSTER, C. B., \& SKINNER, B. F. (1957). Schedules of reinforcement. New York: Appleton-Century-Crofts. 
GENTRY, W. D. (1968). Fixed-ratio schedule-induced aggression. Journal of the Experimental Analysis of Behavior, 11, 813-819.

GoTT, C. T., \& WeIss, B. (1972). The development of fixed-ratio performance under the influence of ribonucleic acid. Journal of the Experimental Analysis of Behavior, 18, 481-497.

Hutchinson, R. R., Azrin, N. H., \& Hunt, G. M. (1968). Attack produced by intermittent reinforcement of a concurrent operant response. Journal of the Experimental Analysis of Behavior, 11, 489-495.
REYNOLDS, G. S. (1968). A primer of operant conditioning. Glenview, IL: Scott, Foresman.

Tномpson, D. M. (1964). Time out from positive reinforcement. Journal of the Experimental Analysis of Behavior, 7, 1-8.

TURNER, L. K., \& LYON, D. O. (1970, May). Schedule-induced aggression as a function of fixed-ratio size. Paper presented at the meeting of the Midwestern Psychological Association, Cincinnati.

(Manuscript received August 9, 1989.) 